\title{
Pelestarian Sardundun Sebagai Budaya Masyarakat Di Desa Tanjung Bulan
}

\author{
Fadhilah Hidayatullah ${ }^{1)}$ \\ FKIP Program Studi Pendidikan Seni Pertunjukan, Universitas PGRI Palembang \\ Jl. Jend.A.Yani Lrg.Gotong Royong, 9/10 ulu Kota Palembang \\ Email :fadhilahhidayatullah@gmail.com
}

\begin{abstract}
This article discusses the results of research on Sardundun's spoken literature in Tanjung Bulan village, Pulau Beringin district (OKU Selatan). The background is the need for local cultural inheritance that has a life value, but has begun to be abandoned by the community. The approach used in this research is qualitative with descriptive methods. The results of this study are to present poetry that contains elements of language and art culture that have local cultural richness in the local area. The purpose of this research is to make the public know that the province of South Sumatra has a culture in Sardundun's speech. The value contained is the principle of life that exists in a creature is to convey gratitude to the creator, which is based on conscience through the medium of the spoken language. Through inheritance, it can be done using the medium of the language spoken. However, it is not limited to oral, but written orally. Initially in the form of spoken speech, now it can only be done by means of written speech. Through local cultural inheritance, it is very appropriate to do it with written media and then tell it. Inheritance is more effectively carried out in educational institutions, because it serves as a forum for learning and teaching. Recommendations for further research, so that it can be used as material for the world of education, so that the transformation of the local Sardundun culture is carried out and its inheritance can be realized. Thus the local culture still exists and exists in the community where the speech was born, and is familiar with the community in general.
\end{abstract}

Keywords: Preservation, Sardundun, Culture.

\begin{abstract}
ABSTRAK
Artikel ini membahas hasil penelitian pada sastra tutur Sardundun yang ada di desa Tanjung Bulan, Kecamatan Pulau Beringin (OKU Selatan). Dilatar belakangi oleh perlunya pewarisan budaya lokal yang mempunyai nilai kehidupan, namun sudah mulai ditinggalkan oleh masyarakatnya. Pendekatan yang digunakan dalam penelitian ini adalah kualitatif dengan metode deskriptif. Adapun hasil dari penelitian ini adalah menyajikan syair yang terdapat unsur budaya bahasa dan seni yang mempunyai kekayaan budaya lokal daerah setempat. Tujuan dilakukan penelitian ini adalah agar masyarakat mengetahui bahwa provinsi Sumatera Selatan memiliki kebudayaan pada sastra tutur Sardundun. Nilai yang terkandung adalah prinsip kehidupan yang ada pada makhluk adalah dengan menyampaikan rasa syukur pada sang pencipta, yang didasari pada hati nurani melalui media bahasa yang dituturkan. Melalui pewarisannya dapat dilakukan dengan media bahasa yang dituturkan. Namun tidak sebatas lisan, akan tetapi lisan yang dituliskan. Awalnya dalam bentuk tuturan yang dilisankan, saat ini hanya dapat dilakukan dengan cara dituturkan melalui media tulis. Melalui pewarisan budaya lokal tersebut sangat tepat dilakukan dengan media tulis kemudian baru dituturkan. Pewarisan tersebut lebih efektif dilakukan di lembaga pendidikan, karena sebagai wadah dalam proses belajar dan mengajar. Rekomendasi untuk dilakukan penelitian lanjutan, sehingga dapat dijadikan sebagai materi untuk dunia pendidikan, sehingga transformasi budaya lokal sardundun terlaksana dan pewarisannya dapat terwujud. Dengan demikian budaya lokal tersebut tetap eksis dan ada ditengah masyarakat tempat tuturan itu lahir, serta familiar ditengah masyarakat pada umumnya.
\end{abstract}

Kata Kunci: Pelestarian, Sardundun, Budaya. 


\section{Pendahuluan}

Budaya pada masyarakat Sumatera Selatan merupakan kekayaan lokal yang sudah seharusnya dibanggakan oleh daerah pemiliknya. Beragam bahasa daerah, terlahir sastra tutur yang beragam pula. Salah satunya adalah bahasa dari etnik Semende. Bahasa tersebut sebagai media tutur pada kesenian sardundun. Bahasa dengan sajian sastra yang di tuturkan secara langsung tanpa melalui proses media tulis. Bentuk sastra yang disampaikan secara lisan atau dituturkan dari mulut ke mulut yang berkembang di tengah masyarakat. Bentuk sastra ini disebut dengan sastra lisan atau sastra tutur, ada juga yang menyebutnya dengan sastra daerah (Kobar Sembilan, 2008:1). Sastra tutur merupakan seni sastra yang dituturkan di tengah masyarakat SumateraSelatan sejak beratus-ratus tahun lalu (Kobar Sembilan, 2008:1).

Kekayaan budaya yang dimiliki oleh suku atau etnik yang ada di Sumatera Selatan belum banyak digali dalam sebuah tulisan. Para pemerhati budaya masih pada sebatas pelaku dan penikmat semata. Namun dalam hal mengapresiasi dan mengekspresikan untuk mewariskan dalam dunia pendidikan belum tersampaikan. Inilah salah satu alasan peneliti ingin melakukan penelitian terkait dari sastra tutur sardundun yang ada di Desa Tanjung Bulan Kecamatan Pulau Beringin (OKU Selatan). Peneliti sebelumnya juga berpendapat bahwa perlunya melestarikan budaya lokal agar tidak punah (Efrianto, 2016).

Kesenian ini mengandung nilai budaya yang terdapat pada syairnya. Untuk itu, melalui penelitian ini menjadi awal dalam menyajikan data yang sangat mendasar. Sehingga dari berbagai disiplin ilmu dapat melanjutkan penelitian pada sudut pandang dari latar belakang keilmuannya masing-masing. Maka dari itu, yang menjadi fokus penelitian ini adalah upaya untuk melestarikannya.

Selain dari pada itu, akan di deskripsikan juga terkait makna yang disampaikan pada tuturan sardundun tersebut. Sardundun ini merupakan kesenian tutur yang mirip dengan guritan. Namun sardundun ini hanya disajikan pada acara tertentu saja, yang dilakukan pada pembuatan rumah kayu. Setelah rumah kayu tengah terpasang atau kerangka dari rumah telah terpasang, baru kesenian ini mulai dituturkan. Adapun tujuan dari kesenian ini dilakukan tiada lain sebagai budaya dari daerah tersebut. Artinya setiap ada pembangunan rumah selalu dilakukan prosesi dari kebudayaan tersebut. Dengan fenomena tersebutlah dipandang perlu untuk dilakukan transformasi dalam pewarisan budaya.

Untuk melestarikan sastra tutur sardundun perlu diketahui nilai-nilai yang terkandung pada isi teks atau syair pada sastra tutur sardundun itu sendiri. Nilai yang terkandung dapat ditinjau dari nilai budaya yang dilihat pada bahasa yang digunakan. Nilai Budaya merupakan sesuatu yang urgen karena dijadikan sebagai seperangkat keyakinan yang mempengaruhi sikap dan perilaku seseorang atau kelompok dalam kehidupan masyarakat
(Nanik Hindaryatiningsih, 2016 :108). Koentjaraningrat (2009: 67) kebudayaan daerah sama dengan konsep kebudayaan daerah, sama dengan konsep suku bangsa. Suatu suku bangsa tidak terlepas dari pola kegiatan masyarakat. Keragaman bergantung pada faktor-faktor geografis. Semakin besar wilayahnya maka komplek perbedaan kebudayaan satu dengan yang lain (Ryan Prayodi \& Endang Danail, 2016: 62).

Oleh karena itu, nilai yang termuat pada tuturan sardundun dipandang perlu untuk dilestarikan sebagai salah satu kebudayaan yang telah mengakar dari masa kemasa. Namun kondisi saat ini sangat memprihatinkan karena sulit untuk disaksikan dalam bentuk upacara yang utuh. Berangkat dari fenomena tersebut, dipandang perlu untuk digali nilai-nilai yang terkandung pada sastra tutur sardundun yang ada di daerah tersebut. Dengan demikian, tepat bahwa setiap kebudayaan yang ada di Nusantara perlu untuk dilestarikan dengan cara melakukan transformasi terhadap regenerasi.

Tempat yang dipandang paling tepat adalah di dunia pendidikan, baik lembaga swasta maupun pemerintah. Karena lembaga pendidikan sebagai wadah generasi anak bangsa melaksanakan proses belajar. Oleh karena itu dapat dikenalkan pada anak bangsa melalui kegiatan pembelajaran. Dengan demikian, penelitian tersebut dirumuskan pada pelestarian sardundun sebagai sastra tutur budaya lokal yang ada di desa Tanjung Bulan. Maka disusun pada pertanyaan sebagai berikut. "Bagaimana upaya pelestarian sardundun sebagai sastra tutur budaya lokal yang ada di desa Tanjung Bulan Kecamatan Pulau Beringin (OKU Selatan)?.”

\section{Kajian Pustaka}

Sardundun merupakan kebudayaan yang dituturkan dengan syair yang indah. Sebagaimana diungkap oleh Koentjaraningrat (2009:166) bahwa unsur universal kesenian yang dapat berwujud gagasan, ciptaan pikiran, ceritera dan syair yang indah. Hal tersebut terdapat pada seni tutur sardundun yang mengandung gagasan yang tercipta dari hasil pikiran manusia, sehingga tercipta cerita-cerita tentang budaya yang dibawakan dengan syair yang indah. Syair yang indah tersebut dibawakan dengan isi cerita yang mengandung nilai-nilai kehidupan sebagai rasa syukur terhadap sang pencipta melalui upacara adat yang telah berjalan sesuai dengan aturan adat dan kebiasaan masyarakatnya. Dengan hal tersebut perlu dilakukan pewarisan budaya lokal dengan cara melestarikannya.

Pelestarian adalah salah satu kegiatan yang tidak dapat dipisahkan dalam ruang lingkup perpustakaan, pelestarian kedengarannya mungkin sangat sederhana, dalam bahasa Indonesia. Istilah pelestarian berasal dari bahasa Sansekerta, yakni "lestari" yang berarti terpelihara. Sedangkan dalam bahasa Inggris, pelestarian disebut dengan resevasion artinya dengan perservasi dapat menjaga, sehingga dapat bertahan lama (Bu'ang, Anggraini, Abarwati \& Fadilah, 2018: 101).

Pelestarian adalah upaya untuk menjaga kesinambungan yang menerima perubahan dan 
pembangunan (berbeda dengan preservasi yang lebih diartikan sebagai pengawetan (Titi Handayani, 2011). Upaya melestarikan sastra tutur sardundun yang ada di Desa Tanjung Bulan Kecamatan Pulau Beringin (OKU Selatan), perlu diketahui terlebih dahulu bentuk tuturan yang menjadi salah satu kebudayaan pada masyarakat setempat berada. Adapun dalam upaya pelestariannya dapat ditinjau pada sudut pandang unsur budayanya yakni bahasa dan seni. Karena tuturan tersebut merupakan sajian syair yang indah yang dibawakan dengan irama kekhasannya.

\section{Metode Penelitian}

Penelitian ini menggunakan metode deskriptif kualitatif, sehingga data yang diperoleh akan dideskripsikan. Metode deskriptif adalah "suatu metode dalam pencarian fakta status kelompok manusia, suatu objek, suatu kondisi, suatu sistem pemikiran ataupun suatu peristiwa pada masa sekarang dengan interprestasi yang tepat (Sudarmayanti, dkk., 2002: 33)."

Adapun data didapatkan dengan melalui observasi, wawancara dan dokumentasi terhadap para pelaku dan tokoh budaya sardundun. Sedangkan teknik yang dilakukan yakni dengan cara merekam audio dan video, serta membuat catatan penting dari seluruh data yang di anggap penting. Senada dengan yang dikemukakan oleh Poham (dalam Prastowo, 2011: 208) bahwa "teknik pengumpulan data adalah cara yang di pakai untuk mengumpulkan informasi." Kemudian juga sebagai langkah yang paling strategis dalam penelitian karena tujuan utama penelitian adalah mendapatkan data (Sugiyono dalam Prastowo, 2011: 208).

Seluruh data yang di dapat, dilakukan analisa dengan cara mendengarkan dan melihat dalam kegiatan analisa, kemudian di tuliskan dalam sebuah tulisan yang mengacu pada jawaban rumusan permasalahan. Dengan demikian, data dapat dihasilkan dan disajikan dalam kalimat deskriptif kualitatif.

\section{Pembahasan}

Berdasarkan hasil penelitian yang dilakukan dengan wawancara dan dokumentasi, sehingga diperoleh datadata yang akan di deskripsikan sedemikian rupa. Adapun hasil gabungan percakapan peneliti dengan informan yakni Bapak H.Ahmad Kordin dan Idirman pada bulan September 2020 yang lalu, sehingga diinterpretasikan sebagai berikut.

Kata sardundun diklasifikasikan menjadi dua suku kata, yakni "sar" dan "dundun". "Sar" dapat dikategorikan sebagai "sari", yang bermakna "isi". Sedangkan "dundun" mempunyai persamaan kata pada "betundun" yang mempunyai arti "berangkaian". Maka sari berdundun adalah segala rangkaian yang berisi tentang budaya masyarakat daerah semende dalam pembangunan rumah. Hal tersebut sebagai bentuk rasa syukur terhadap sang pencipta, yang terdapat pada syair sardundun itu sendiri.

Sardundun merupakan kebudayaan yang telah dilakukan oleh masyarakat Semende dari masa ke masa yang telah lama terjadi pada masyarakat semende di desa
Tanjung Bulan, kecamatan Pulau Beringin (OKU Selatan). Kemasan yang dilakukan melalui upacara adat yang telah berjalan dari zaman dahulu hingga saat ini. Kebudayaan ini berkembang berkisar tahun 1968 dari seorang tokoh "Abu Sahin bin Kenadon" kemudian diteruskan oleh anaknya, yaitu Idirman bin Abu Sahin. Kebudayaan ini bertujuan untuk meminta keselamatan atas rumah yang baru dibangun. Upacara dilakukan untuk pertama kali sebelum atap rumah panggung di pasang. Ditengah upacara berlangsung, sardundun berisikan tembang yang merdu, umumnya dibawakan oleh seorang laki-laki yang berusia 50 tahun keatas. Melalui upacara tersebut dihadiri oleh masyarakat sekitar. Baik dari tokoh masyarakat, agama, maupun pihak pemerintah serta keluarga besar dari pemilik hajat upacara tersebut. Disamping itu juga tidak sedikit terdapat anak yang berlomba menghadiri upacara. Sardundun dituturkan di atas rumah sambil membagikan uang logam dengan cara dijatuhkan dari atas, hingga anak-anak berlomba untuk mengambil uang logam tersebut. Hal tersebut sebagai tanda syukur terhadap sang maha kuasa atas rumah yang telah dibangun. Tidak sedikit juga yang hadir diluar dari undangan yang berperan sebagai penikmat dan penonton saat sardundun di tuturkan dengan syair yang indah. Hal tersebut menunjukan adanya penyelenggara dan penonton. Hal tersebut senada dengan apa yang telah diungkap oleh Koentjaraningrat bahwa saat kesenian dapat berwujud tindakan-tindakan interaksi yang dapat dilakukan penyelenggara dan penonton. Hal yang diselenggarakan dan ditonton tiada lain hasil dari unsur kebudayaan yakni bahasa dan seni.

Berdasarkan unsur kebudayaan yang ada pada konsep Koentjaraningrat, dapat ditinjau dari Bahasa dan Seni. Dari sudut pandang bahasa dapat dilihat dari dealeg / tata bahasa yang perlu dipertahankan sebagai pewarisan budaya lokal. Sedangkan sudut pandang seni dapat dilihat dari syair yang dituturkan dengan indah. Tuturan syair tersebut yang disajikan dengan senandung irama yang khas diikuti dengan kenikmatan rasa dalam menguntai kata-kata dengan senandung yang berisi irama khas daerah setempat.

Berangkat dari kedua unsur kebudayaan tersebutlah perlu digali muatan isi yang ada pada tuturan sardundun. Dengan demikian perlu dilakukan pewarisan karena mengandung budaya lokal yang kaya akan nilai kehidupan. Oleh karenanya, perlu dikenalkan dan dipelajari. Selain itu, bagi peneliti lanjutan dapat juga melakukan penelitian berdasarkan sudut pandang keilmuannya. Sehingga akan memperoleh materi konteks seni sardundun yang dapat disusun untuk dijadikan sebagai ajang pewarisan seni budaya lokal yang ada di Provinsi Sumatera Selatan.

Selain dari sudut pandang seni dapat dilihat pula pada sudut pandang tata dan gaya bahasa. Karena gaya bahasanya kaya akan ciri dan khasnya yang menyatu pada syair sardundun itu sendiri. Oleh sebab itu, keilmuan yang berlatar belakang sastra dan bahasa dapat mengembangkan keilmuannya melalui penelitian dan kajian pada budaya masyarakat semende tersebut. Untuk 
itu dapat dipelajari oleh anak didik di dunia pendidikan. Bahasa yang digunakan oleh suku Semende mempunyai ciri dan karakter tersendiri. Adapun syair sardundun yang diperoleh melalui media rekam audio. Rekaman audio tersebut didapat saat menemui salah satu pewaris budaya sardundun, sekaligus sebagai penutur. Peneliti melakukan rekaman dengan beberapa kali, guna menjaga terjadi kekeliruan dalam tahap penulisannya. Adapun hasil dari audio rekam tersebut di analisa berulang-ulang melalui pendengaran dan ditranskripsikan sebagai berikut.

1. Assalamualaikum bumi kupuji kate ratu bejulang Assalamualaikum langit kupuji kate ratu bejulang

Bumi ade setapak miring

Langit ade selibae payung

Ratu bejulang la nantanlah

2. Nenek ratu bejulang ade

Cite-cite nak negak gedung di ulu, nak negak gedung di ilie

Kate nenek ratu bejulang

3. Assalaualaikum jeme banyak dengaeilah kate

Kate tuturan ratu bejulang

Kaum lime ade lime

Mintak gimbari gedung di ulu

Kate tutur nenek ratu bejulang

Mane kate-kete, nian tunggu-tunggulah nian

Mane tetap-tetap nian

4. Terus ganjur bejalan ratu bejulang

Tanah di mane dikde ditapak

Gunung mane dikde ditentang

Luwang mane dikde idup li ratu bejulang

Itu kate genulang-genalik kate (pemikiran bolakbalik)

Tadi kate kele ngulang pule

5. Itulah nak nengaeannye li jeme banyak Idup li ratu bejulang

6. Sampai kegunung mangkak mingkik

Sampai kegunung gentak genting

Sampai kelubuk liku ujung tanjung

Ratu bejulang la padaelah

7. Menentang gunung ditentang

Pule menentang laut selibae, selupat aur gading

Sampai kegunung mangkak mingkik

Sampai kegunung gentak genting

Sampai kelubuk liku ujung tanjung

Ratu bejulang la nantanlah

8. Ading kumalang Raden Kiunang name

Dingku malang abis bulan begenti bulan

Abis taun begenti taun

Menunggui kayu rimbun serumpun daun

Kayu redak kayu redaian

Sude dibukur sude dikaruh
Anggapan raden kiunang

9. Cite-cite lalaju nian

Sude dipotong, sude dilebur

Pandak panjang la njadi sake

Pandak panjang la njadi jenang

Panjang semegi mbak serepat diukurnye

10. Itu kate genulang-genalik

Kate tadi ngulang pule

Amu kate pembohongnye

Amu ngguk nian lanyate mbak ini

Bukannye agi kayu redak kayu redaian

Bukannye agi kayu rimbun serumpun daun

Mbak ini la njadi kayu lenggak kayu lenggame

La njadi gedung di tengah

La kandik meripat anak cucung ratu bejulang

11. Ading kumalang raden kiunang name

Dingku malang abis bulan begenti bulan

Abis taun begenti taun

Menunggui kayu rimbun serumpun daun

Kayu redak kayu redaian

Sude dibukur, sude dikaruh

Anggapan raden kiunang

Mbak serepat, mbak dikulak

Serincong mbak li tabung

12. Mane-mane anak cucung kena

Cingkuk-pingkul bute-behabe

Sape calak dapat

Sape canggih, hulih

Kursemangai kundu

Mintak dilindungi mane-mane anak cucung puyang awak raje nyawe

Reti puyang awak raje nyawe kandik melindungi sedak denye anak cucungnye

Kursemangai-kursemangai-kursemangai kate ratu bejulang

Setelah syair dari sardundun yang menggunakan bahasa aslinya telah terurai, maka diuraikan pula dalam bentuk hasil transkripsi yang menggunakan bahasa Indonesia. Hal tersebut menyatu dengan makna yang terkandung pada syair tersebut. Dengan demikian peneliti mentranskripsikan dengan bahasa Indonesia sekaligus membongkar maksud dari syair disetiap kalimatnya. Melalui kajian makna naskah, peneliti didampingi oleh informan yakni H.Ahmad Kordin sehingga bahasa-bahasa yang di anggap sulit dan asing dapat teratasi. Adapun hasil transkripsinya dan sekaligus makna yang terdapat pada syair sardundun diuraikan sebagai berikut.

1. Assalamualaikum bumi kupuji kata "ratu bejulang". ratu bejulang merupakan nama tetua atau nenek moyang. Kemudian dilanjutkan dengan kalimat kedua, yakni: "Assalamualaikum langit kupuji kata ratu bejulang". Baris pertama dan kedua merupakan bahasa dalam memuji bumi dan langit. Sedangkan 
bumi ada setapak miring merupakan bumi lebih kecil dari telapak kaki yang seutuhnya. Kemudian, "Langit ada selebar payung,

Ratu bejulang sudah nyata". Maksudnya adalah lebih dahulu ratu bejulang, baru tercipta bumi dalam hal ini cahayanya bukan wujudnya.

Kemudian dilanjutkan dengan syair yang berikutnya.

2. Nenek Ratu Bejulang ada

Cita-cita mau mendirikan tempat tinggal (Rumah)

Kata nenek Ratu Bejulang

3. Assalamualaikum orang banyak dengarkanlah

Pesan Ratu Bejulang

Kaum lima itu, ada lima

Tolong doakan tempat tinggal (rumah)

Pesan nenek Ratu Bejulang

Yang sudah dikatakan, tunggulah (yang sudah dikatakan agar dilaksanakan sesuai dengan kenyataan).

Maksud dari syair urutan nomor tiga diatas adalah bahwa Ratu Bejulang menyampaikan tentang pengurus agama, pada umumnya didalam masjid ada lima, yakni ketib, bilal, marbut, datuk, dan imam. Melalui pesan tersebut ada sesuatu tujuan yang dimaksudkan, yakni untuk mendoakan atas rumah yang sudah nyata terbangun.

4. Terus ganjur bejalan Ratu Bejulang, artinya adalah lanjutkan perjalanan rencana.

Tanah di mana tidak dilihat

Gunung yang mana tidak ditentang

Jurang yang mana ratu bejulang tidak hidup

Dalam hal ini untuk memilih tanah yang akan dibuat bangunan rumah kayu.

5. Itulah ceritanya hidup seorang Ratu Bejulang

6. Sampai ke gunung bukit-bukit berbatuan yang tidak datar (mangkak mingkik)

Sampai kegunung terpotong-potong (gentak genting)

Sampai ke air ujung (ke lubuk liku ujung tanjung)

Ratu bejulang sudah menerima kenyataan/ pasrah (la padaelah)

7. Menentang gunung ditentang

Juga menentang laut selebar, selupat aur gading

Sampai ke gunung mangkak mingkik

Sampai ke gunung gentak genting

Sampai ke ujung air

Ratu Bejulang sudah nyata

8. Nama Adik kusayang adalah Raden Kiunang

Adikku sayang, habis bulan berganti bulan

Habis tahun berganti tahun

(baris ke-dua dan ke-tiga, bermakna waktu terus berjalan)

Menunggui kayu rimbun serumpun daun

Kayu "redak" kayu "redaian" (Julukan nama kayu dengan pujian)
Sudah "dibukur" (ditandai), sudah "dikaruh" (diberi ciri-ciri)

Anggapan raden kiunang

9. Cita-cita sudah tercapai

Sudah di potong, sudah di ukur

Ukuran Pendek dan panjang sudah menjadi (sake)/ tiang rumah yang terletak pada lantai ke-dua dan berikutnya

Ukuran pendek dan panjang sudah menjadi kusen/ tiang yang difungsikan untuk jendela dan pintu

Ukuran panjang sama pengukurannya

10. Itu kata (genulang-genalik) pemikiran bolak balik

Kata yang sudah terucap, kembali terfikir

Kalau kata bohongnya

Memang sudah nyata seperti ini

Bukan lagi (kayu redak kayu redaian)/ julukan nama kayu dengan pujian

Bukan lagi kayu rimbun serumpun daun

Sekarang sudah menjadi (kayu lenggak kayu lenggame)/ julukan kayu yang sudah siap dipakai atau digunakan untuk pembangunan tempat tinggal, dalam hal ini rumah

Sudah menjadi rumah

Untuk perkumpulan dalam kehidupan anak cucu Ratu Bejulang di kemudian hari akan datang

11. Nama Adik kusayang adalah Raden Kiunang

Adikku sayang, habis bulan berganti bulan

Habis tahun berganti tahun

(baris ke-dua dan ke-tiga, bermakna waktu terus berjalan)

Menunggui kayu rimbun serumpun daun

Kayu redak kayu redaian (Julukan nama kayu dengan pujian)

Sudah ditandai "dibukur", sudah diberi ciri-ciri "dikaruh"

Anggapan Raden Kiunang

"Mbak serepat" sudah selaras, mbak dikulak (alat ukuran)

Serincung mbak li tabung (perumpamaan kesamaankesamaan ukuran kayu)

12. Mana-mana anak cucu dia. "kena" (menyatakan Ratu Bejulang)

Sehingga tidak kelihatan

Siapa "calak" pintar ia yang dapat

Siapa yang canggih) cepat ia juga akan mendapatkan

Kursemangai, kundu (mensyukuri nikmat yang telah nyata kelihatan)

Agar dilindungi seluruh anak cucu "puyang awak" (tetuah) "raja nyawa" (pujian)

"Puyang awak raja nyawa" artinya untuk melindungi seluruh anak cucu nya

Kursemangai-kursemangai-kursemangai kate Ratu Bejulang (mensyukuri nikmat yang telah nyata kelihatan, kata Ratu Bejulang. 
Syair sardundun tersebut diterjemahkan oleh Fadhilah Hidayatullah sebagai peneliti. Sedangkan naskah sardundun itu sendiri bersumber dari hasil rekaman yang dituturkan oleh Bapak Idirman Bin Abu Sahin. Dilengkapi oleh Bapak H.Ahmad Kordin Bin H.Sulmani sebagai narasumber dalam kajian makna naskah sardundun.

Makna yang tersirat pada syair sardundun adalah hubungan antara makhluk dan sang pencipta. Makhluk mempunyai rasa syukur terhadap tuhannya melalui rasa yang dituangkan melalui media syair yang dituturkan, disesuikan dengan jalannya upacara daerah masyarakat setempat.

\section{Kesimpulan}

Untuk melestarikan sardundun dapat dikenalkan melalui unsur kebudayaan yakni bahasa dan seni. Melalui bahasa sangat kaya akan gaya dan tata bahasanya. Melalui bahasa sastra yang disampaikan dalam memuji alam semesta serta isinya, sebagai bentuk pujian kepada yang maha pembuat Alam Semesta yakni Sang Pencipta. Semata-mata atas kehendak dan karunia yang diberikan oleh sang Pencipta lah, semua dapat terwujud dan terlaksana dalam bentuk dan wujud yang nyata.

Senada dengan ungkapan Kordin, Ahmad (dalam jurnal Sitakara, volume 4, nomor 1, tahun 2019) yang menyatakan bahwa fungsi dari kesenian sebagai media nenek moyang terdahulu, untuk menyampaikan maksud kepada pihak lain, baik kepada Tuhan melalui uraian lantunan pada kenjun (irama melodi) pantun.

Atas dasar syukur tersebut, diuraikanlah tuturan yang dengan sendirinya terucap dari mulut dan lidah yang diiringi dengan hati dengan penuh perasaan yang lembut. Berawal dari rasa yang amat dalamlah, sehingga seni hadir dalam jiwa penutur. Maka seni hadir dalam tatanan bahasa yang dilakukan dengan sastra yang indah. Dengan demikian, pada sudut pandang seni, mempunyai estetika tersendiri. Dapat dilihat dan dirasakan pada gaya dan irama senandung syair sardundun itu sendiri. Syair tersebut disajikan dengan merdu sesuai dengan rasa syukur terhadap sang pencipta.

Dengan demikian, sardundun dapat diwariskan dengan cara mentransformasikan melalui bahasa yang disyairkan atau dituturkan dengan irama yang indah. Teknik dalam transformasi tersebut adalah dengan cara memahami terlebih dahulu makna dan syair sardundun. Setelah itu masuk pada teknik estetika pada ciri dan karakter dalam sudut pandang irama dalam penyajian sastra tutur sardundun itu sendiri yaitu dengan cara dan teknis dalam menuturkannya.

\section{Daftar Pustaka}

Bu'ang, M., Anggraini, R., Abarwati, S. T., \& Fadilah, z. 2018. Pelestarian Bahan Pustaka di Musium Bala Putra Dewa Sumatera Selatan. Iqra vol 12 no 01, 99-115.

Efrianto. 2017. Struktur Masyarakat Semende di Kabupaten Ogan Komering Ulu Selatan. Jurnal Penelitian Sejarah dan Budaya, Vol. 3 No. 1, 617-635.

Hidayatullah, Fadhilah. 2019. Materi Perkuliahan Sastra Tutur Sumatera Selatan. Bandung: Penerbit Manggu Makmur Tanjung Lestari.

Hidayatullah, Fadhilah. 2019. Pemaknaan Syair dan Kenjun dalam Seni Rejung Ringit bagi Masyarakat Semende (di Desa Tanjung Bulan Kecamatan Pulau Beringin Kabupaten OKU Selatan Provinsi Sumatera Selatan). Sitakara, volume 4, nomor 1 .

Koentjaraningrat. 2009. Edisi Revisi. Pengantar Ilmu Antropologi. Jakarta: PT.Rineka Cipta

Nanik, Hindaryatiningsih. 2016. Model Proses Pewarisan Nilai-nilai Budaya Lokal dalam Tradisi Masyarakat Buton. Universitas Haluoleo kendari

Prastowo, Andi. 2011. Metode Penelitian Kualitatif dalam Perspektif Rancangan Penelitian. Jogjakarta: Ar-ruzz Media.

Ryan Prayodi. 2016. Pergeseran Nilai-Nilai Budaya Pada Suku Bonai Sebagai Civic Culture Dikecamatan Bonai Darusalam Kab. Rokan Hulu Prov. Riau. Universitas Pendidikan Indonesia.

Sembilan Kobar. 2008. Sastra Tutur Sumatera Selatan Peran dan Fungsinya dalam Masyarakat: Dinas Kebudayaan dan Pariwisata Provinsi Sumatera Selatan.

Sudarmayanti, dkk. 2002. Metode Penelitian. Bandung: CV. Mandar Maju.

Titi Handayani. 2011. Identifikasi Karakteristik Façade Bangunan untuk Pelestarian Kawasan Pusaka di Ketandan. Yogyakarta.

\section{Narasumber:}

Ahmad Kordin (69), Seniman Sardundun dan Tokoh Masyarakat Semende Darat, Dusun Tanjung Bulan Kecamatan Pulau Beringin Kabupaten OKU Selatan.

Idirman (70), Seniman Sardundun Dusun Tanjung Bulan Kecamatan Pulau Beringin Kabupaten OKU. 